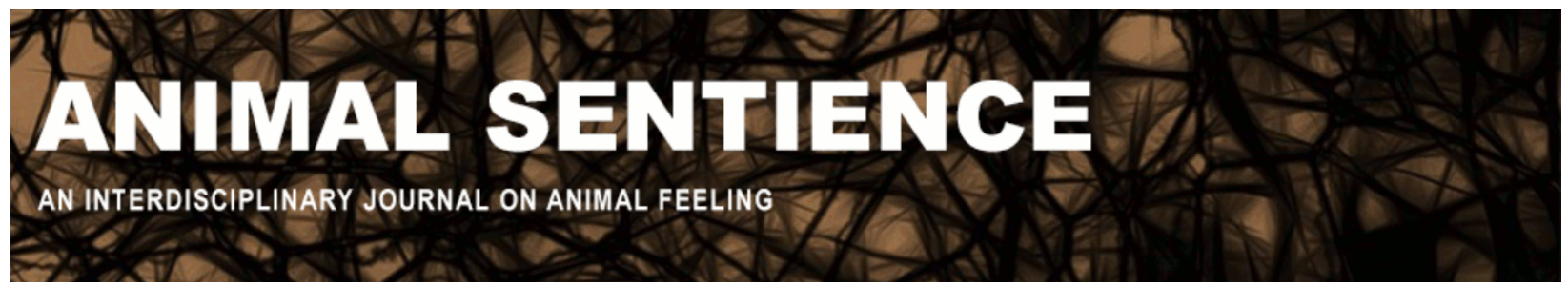

Burghardt, Gordon (2016) Mediating claims through critical anthropomorphism. Animal Sentience 3(17)

DOI: $10.51291 / 2377-7478.1063$

Date of submission: $2015-11-10$

Date of acceptance: 2015-12-13

(c)

This article has appeared in the journal Animal

Sentience, a peer-reviewed journal on animal

cognition and feeling. It has been made open access,

free for all, by WellBeing International and deposited

in the WBI Studies Repository. For more information,

please contact

wbisr-info@wellbeingintl.org.

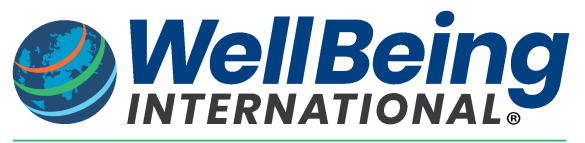

SOLUTIONS FOR PEOPLE, ANIMALS AND ENVIRONMENT 


\title{
Mediating claims through critical anthropomorphism
}

\author{
Commentary on Key on Fish Pain
}

\author{
Gordon M. Burghardt \\ Departments of Psychology and Ecology \& Evolutionary Biology \\ University of Tennessee
}

\begin{abstract}
Key's (2016) discussion of his claim that fish do not feel pain ignores the history of attempts to study the attribution of mental states to other species. Although willing to accept that mammals feel pain, Key claims that fish lack the mammalian neural mechanisms underlying pain and are unconscious of their experiences. Consequently, we do not need to be overly concerned about fishing practices that would otherwise be viewed as painful. Key uses a flawed anthropomorphic lens. All attributions of mental events to organisms other than oneself involve inferences derived from anthropomorphic processes through which we process physiological and behavioral data. To do this effectively we need to employ a critical anthropomorphism incorporating our experiences as sentient beings along with diverse scientific findings, avoiding claims that some types of data always trump other considerations.
\end{abstract}

\begin{abstract}
Gordon M. Burghardt gburghar@utk.edu is Alumni Distinguished Service Professor at the University of Tennessee, Knoxville. He has worked primarily on reptile behavior and animal play. However, he has published on animal ethics issues for 35 years and has advocated a critical anthropomorphism as well as an appreciation of historical treatments of animal mentality. http://web.utk.edu/ gburghar/
\end{abstract}

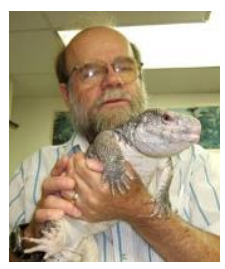

"Our anthropocentric way of looking at things must retreat further and further, and the standpoint of the animal must be the only decisive one" (von Uexküll, 1909/1985, p. 223).

The above epigraph is one I used years ago (Burghardt, 1991), but it is appropriate here as well.

Key's (2016) target article is clear in its goals and conclusions. His main contention is in the last sentence of the abstract: "... fish lack the necessary neurocytoarchitechture, microcircuitry and structural connectivity necessary for the neural processing required for feeling pain." But despite Key's forceful prose and assertions, things are not quite that conclusive. Those who accept that other species have mental states - and hence disagree with Key - also need to avoid traps set by their protagonists. One of these traps is to shift the focus, as in Key's first paragraph, from pain to the much broader concept of consciousness and problems in defining and recognizing "consciousness" rather than sticking to the topic under discussion: the nature and importance of the neural and behavioral aspects of pain and aversive states in general. My dictionary defines "sentience" as "a state of elementary or undifferentiated consciousness." This sets the bar rather low. I will argue here that consciousness is not the key issue at all. 
When Griffin began his advocacy of cognitive ethology and published his influential little book (Griffin, 1976), he omitted the entire early literature on animal mentality, specifically Romanes (1883) and, to a lesser extent, Morgan (Burghardt, 1985). The charge of anthropomorphism was hurled at Griffin, just as it had been at the earlier authors, especially Romanes. And although many of the examples used have indeed been anecdotal and uncritical, it is just as uncritical an error to omit the perspective of the animal (or another person; Rivas \& Burghardt, 2002). Like consciousness, anthropomorphism can mean many different things. I have accordingly advocated a critical anthropomorphism in which our "statements about animal joy and suffering, hunger and stress, images and friendships, are based on careful knowledge of the species and the individual, careful observation, behavioral and neuroscience research, our own empathy and intuition, and constantly refined publically verifiable predictions" (Burghardt, 1997: 268).

Key might feel encouraged by a recent detailed analysis of how we use our cognitive abilities and biases to attribute mental states to nonhuman entities (Urquiza-Haas \& Kotrschal, 2015). However, in neurobiology, a rapidly developing field with a changing conceptual and methodological landscape, a general conclusion should not be based on selected data derived from a few species. Neurobiology is littered with claims about species that could or could not see color or discriminate wavelengths, but behavioral experiments have often shown that color perception is context-specific and cannot be predicted on the basis of structure alone (Kelber, Vorobyev, \& Osario, 2003). There have also been claims that reptiles, having only a reptilian brain, could not have positive emotions (MacLean, 1985, 1990); or, more recently, that animals "below" reptiles could not play because they do not have emotions and thus consciousness (Burghardt, 2005; Cabanac, 1999). Despite confident earlier assertions to the contrary (e.g., Maier \& Schneirla, 1935), in recent decades numerous cognitive skills have been discovered that had been thought to be beyond the ability of ectothermic animals (e.g., Bshary, Wickler, \& Fricke, 2002). Whether these abilities need to be accompanied by "consciousness," is not as critical to decisions about animal welfare as behavioral continuity. We need to get beyond arguments invoking either neural analogical inference or subjective analogical inference points made long ago (Burghardt, 1985) and not, I believe, effectively refuted. As a recent book on dog behavior points out, studies focused on classical ethological analysis along with basic learning processes can foster more understanding than some current anthropocentric interpretations of dogs (Coppinger \& Feinstein, 2015). This stance seems applicable to fish as well as to uncritical anthropocentrism (Burghardt, 2007).

A short commentary cannot do justice to the topic, but it should also be noted that many fishes have large brains; mormyrids have huge cerebellums, covering the entire surface of the brain (Butler \& Hodos, 1996), with a larger brain to body mass ratio (4.4\%) than humans (Bullock, 1977). Hence claims that pain, in the human or even mammalian sense, is absent in these animals are perhaps not as germane as the need to avoid the horrible mistreatment of complex creatures with multifaceted cognitive and behavioral abilities that we are only beginning to fathom. Financial costs to the fishing industry should not blind us to what we think is problematic. Society is implementing more humane rearing and slaughter of cows, chickens, and 
other domesticated animals without demanding detailed neuroscientific support for each change in procedure. Is Key perhaps not being critical enough in accepting the neuroscientific rationale that is being invoked to justify cruel treatment of "alien" beings rather than honestly admitting that this is just a case of human interests trumping other factors?

Although the nature of subjective experience is only partially accessible to objective science, we must keep trying to understand it despite current scientific limitations. Toward this end, I think it is essential to develop a fifth aim for ethology concerning the private experiences of "the other," without bringing in human consciousness as the essential barometer (Burghardt, 1985, 1997). I will leave it to other commentators to discuss the behavioral, phylogenetic, and neural research addressing Key's claims. Although I think Key is too wedded to neural reductionism, his provocative thesis on a currently timely topic does deserve to be carefully discussed and evaluated.

\section{References}

Bullock, T. H. (1977). Introduction to nervous systems. San Francisco: W. H. Freeman.

Burghardt, G. M. (1985). Animal awareness: current perceptions and historical perspective. American Psychologist, 40, 905-919.

Burghardt, G. M. (1991). Cognitive ethology and critical anthromorphism: a snake with two heads and hognose snakes that play dead. In C. A. Ristau (Ed.), Cognitive ethology: the minds of other animals (pp. 53-90). San Francisco: Erlbaum.

Burghardt, G. M. (1997). Amending Tinbergen: a fifth aim for ethology. In R. W. Mitchell, N. S. Thompson, \& H. L. Miles (Eds.), Anthropomorphism, anecdotes, and animals (pp. 254-276). Albany: SUNY Press.

Burghardt, G. M. (2005). The genesis of animal play: testing the limits. Cambridge: MIT Press.

Burghardt, G. M. (2007). Critical anthropomorphism, uncritical anthropocentrism, and naive nominalism. Comparative Cognition and Behavioral Reviews, 2, 136-138.

Butler, A., B., \& Hodos, W. (1996). Comparative vertebrate neuroanatomy: evolution and adaptation. New York: Wiley-Liss.

Cabanac, M. (1999). Emotion and phylogeny. Journal of Consciousness Studies, 6, 176-190.

Coppinger, R., \& Feinstein, M. (2015). How dogs work. Chicago, IL: University of Chicago Press. Griffin, D. (1976). The question of animal awareness. New York: Rockefeller University Press.

Kelber, A., Vorobyev, M., \& Osario, D. (2003). Animal colour vision - behavioural tests and physiological concepts. Biological Reviews, 78, 81-118.

Key, B. (2016). Why fish do not feel pain. Animal Sentience 2016.003.

MacLean, P. (1985). Brain evolution relating to family, play and the separation call. Archives of General Psychiatry, 42, 405-417.

MacLean, P. (1990). The triune brain in evolution. New York: Plenum.

Maier, N. R. F., \& Schneirla, T. C. (1935). Principles of animal psychology. New York: McGrawHill.

Rivas, J., \& Burghardt, G. M. (2002). Crotalomorphism: a metaphor for understanding anthropomorphism by omission. In M. Bekoff, C. Allen, \& G. M. Burghardt (Eds.), The 
cognitive animal: theoretical, methodological, and empirical approaches. Cambridge: MIT Press.

Romanes, G. J. (1883). Mental life of animals. London: Kegan, Paul, Trench, Trübner, \& Co.

Uexküll, J. von (1985). Environment (Umwelt) and the inner world of animals (C. J. Mellor \& D. Gove, Trans.). In G. M. Burghardt (Ed.), The Foundations of Comparative Ethology (pp. 222245). New York: Van Nostrand Reinhold. (Reprinted from von Uexküll, J. [ 1909] Umwelt and Innenwelt der Tiere. Berlin: Jena).

Urquiza-Haas, E. G., \& Kotrschal, K. (2015). The mind behind anthropomorphic thinking: attribution of mental states to other species. Animal Behaviour, 109, 167-176. 